\title{
Aetiological Profile of Anaemia in Elderly at a Tertiary Care Centre
}

\author{
Kalpana Chandra ${ }^{1}$, Praveen Kumar ${ }^{2}$, Shuchismita ${ }^{3}$, Arshad Ahmad ${ }^{4}$, Amit Kumar Mishra ${ }^{5}$, \\ Govind Kumar ${ }^{6}$, Manoj Kumar Choudhary ${ }^{7}$, Abhishek Kumar ${ }^{8}$
}

\begin{abstract}
${ }^{1}$ Department of Pathology, Indira Gandhi Institute of Medical Sciences, Patna, Bihar, India. ${ }^{2}$ Department of General Medicine, Indira Gandhi Institute of Medical Sciences, Patna, Bihar, India. ${ }^{3}$ Department of Haematology, Indira Gandhi Institute of Medical Sciences, Patna, Bihar, India. ${ }^{4}$ Department of General Medicine, Indira Gandhi Institute of Medical Sciences, Patna, Bihar, India. ${ }^{5}$ Department of General Medicine, Indira Gandhi Institute of Medical Sciences, Patna, Bihar, India. ${ }^{6}$ Department of General Medicine, Indira Gandhi Institute of Medical Sciences, Patna, Bihar, India. ${ }^{7}$ Department of General Medicine, Indira Gandhi Institute of Medical Sciences, Patna, Bihar, India. ${ }^{8}$ Department of General Medicine, Indira Gandhi Institute of Medical Sciences, Patna, Bihar, India.
\end{abstract}

\section{ABSTRACT}

\section{BACKGROUND}

Anaemia is a common clinical condition in elderly commonly associated with increased morbidity and mortality, increased hospitalization, decreased physical performance, loss of mobility and disability at higher rates than those people without anaemia. The present study was undertaken to assess the aetiological profile of anaemia in elderly.

\section{METHODS}

A cross sectional study was done among elderly patients with anaemia admitted in general medicine department and / or attending general medicine OPD, IGIMS, Patna, Bihar. 100 consecutive patients were selected as per inclusion and exclusion criteria. The patients were subjected to a thorough clinical examination and investigation, and data was analysed.

\section{RESULTS}

Anaemia is more common in males with a male to female ratio of $2.84: 1$. Maximum numbers of cases was in the age range of 61 to 70 comprising $70 \%$ followed by $23 \%$ in 71 to 80 years age group and $6 \%$ in 81 to 90 years age group. Weakness was the most common presentation comprising $74 \%$ cases. Comorbidities in patients along with anaemia were solid malignancy in $5 \%$, diabetes mellitus (DM) in $7 \%$, hypertension (HT) in $6 \%$, chronic kidney disease (CKD) in $5 \%$, cor pulmonale in 3 $\%$ and hypothyroidism in $1 \% .48 \%$ patients were having moderate anaemia and 45 $\%$ patients were having severe anaemia. Morphologically most common variety of anaemia was normocytic normochromic contributing $57 \%$ of the patients. Bone marrow examination done in 62 cases revealed hyper cellular marrow in 27, normocellular in 24, hypo cellular marrow in 6 and mildly hyper cellular to normocellular in 5 cases. Aetiological distribution showed $14 \%$ of anaemia of chronic disease (ACD) and $14 \%$ due to vitamin B12 deficiency. This was closely followed by iron deficiency anaemia (IDA) in $13 \%$ cases.

\section{CONCLUSIONS}

Anaemia in elderly is a common clinical condition commonly presenting with nonspecific symptom. Normocytic normochromic anaemia is the most common morphological type of anaemia with various underlying treatable aetiologies.

\author{
Corresponding Author: \\ Dr. Praveen Kumar, \\ Kailash - 501, Jalalpur Heights, \\ Mansarovar Colony, RPS More, \\ Danapur, Patna, Bihar - 801503, India \\ E-mail: praveen_kmr_23@yahoo.co.in
}

DOI: 10.14260/jemds/2020/614

How to Cite This Article:

Chandra K, Kumar P, Shuchismita, et al. Aetiological profile of anaemia in elderly at a tertiary care centre. J Evolution Med Dent Sci 2020;9(38):2820-2823, DOI: $10.14260 /$ jemds $/ 2020 / 614$

Submission 30-05-2020,

Peer Review 13-08-2020,

Acceptance 20-08-2020,

Published 21-09-2020.

Copyright (C) 2020 Kalpana Chandra et al. This is an open access article distributed under Creative Commons Attribution License [Attribution 4.0 International (CC BY 4.0)]

\section{KEY WORDS}

Anaemia, Anaemia in elderly, MDS 


\section{BACKGROUND}

Anaemia is a clinical condition characterized by decrease in haemoglobin level in the blood below the lower extreme of the normal range for the age and sex of the individual.1,2 Anaemia is defined by the WHO standard as a haemoglobin $<13 \mathrm{gm} \%$ for male and $<12 \mathrm{gm} \%$ for female (non-pregnant), and morphologically classified on the basis of MCV as microcytic (< $80 \mathrm{fL}$ ), normocytic (81 - $98 \mathrm{fL}$ ), or macrocytic (> $98 \mathrm{fL})$. $^{1,2}$

Geriatric patients are patient of more than 60 years age. ${ }^{3}$ In recent past there is explosive growth in number of elderly patients. Among older persons, the oldest old (those $>80$ years of age) are the fastest growing segment of the population. ${ }^{4}$ In the UK, the total population grew by $11 \%$ over the last 30 years, but the number of people aged over 65 years rose by 24 $\% .^{5}$ The steepest rise occurred in those aged over 85 from 600000 in 1981 to 1.5 million in 2011 and this number is projected to increase to 2.4 million by 2026 , while the working age population (20 - 64 years) is expected to grow by only $4 \%$ between 2011 and 2026. In India also there is continuous rise in elderly population. It was 19 million in 1950 and 90 million in 2006 and will be 330 million in 2050, thus showing a increase of $270 \% .^{3}$ Population of age more than 80 years is showing more increment. It was 0.8 million in 1950, 9 million in 2006 which are projected to be 53 million in 2050 i.e. a rise of almost $500 \%{ }^{3}$

Anaemia is a common clinical condition in elderly and prevalence increases with age. This condition is predominantly underdiagnosed in them. Previously decrease in $\mathrm{Hb}$ level was considered as a normal aging phenomenon. However, anaemia in elderly is found to be associated with increased morbidity and mortality, increased hospitalization, decreased physical performance, loss of mobility and disability at higher rates than those people without anaemia. ${ }^{6}$ More than $10 \%$ of community-dwelling adults aged 60 years and older has WHO defined anaemia. Elderly male and female are almost equally affected having prevalence of anaemia 9.2 $\%$ to $23.9 \%$ in male, $8.1-24.7 \%$ in female. In community dwelling adults of more than 85 years of age $25 \%$ of male and $20 \%$ of female are affected by anaemia. In nursing homes, anaemia is present in $48-63 \%$ of residents. ${ }^{7}$ Prevalence of anaemia in Blacks is more than Whites $(33.6 \%$ and $13.8 \%$ respectively). It is probably due to difference in socioeconomic status, health, nutritional behaviour, associated co-morbid condition and probably genetic difference.

We wanted to study the aetiological profile of anaemia in elderly.

\section{METHODS}

A cross sectional study was conducted on anaemic elderly patients admitted in general medicine department and / or attending medicine OPD, IGIMS, Patna, Bihar. The study was approved by ethics committee and informed consent was obtained.

A total of 100 consecutive patients were selected as per inclusion and exclusion criteria. Sample size was calculated by using nMaster 2.0 software keeping precision 5 and confidence interval $95 \%$.

\section{Inclusion Criteria}

All new patients above 60 years of age with

1. $\mathrm{Hb}<13 \mathrm{gm} / \mathrm{dL}$ for male and $\mathrm{Hb}<12 \mathrm{gm} / \mathrm{dL}$ for female

2. Consenting for evaluation for anaemia required for establishing the cause.

\section{Exclusion Criteria}

Refusal for evaluation as per protocol.

- $\quad$ Selected patients were subjected for detail history and clinical examination.

- These patients were subjected for following investigation for establishing the diagnosis.

1. Hemoglobin, red blood cell count, total leukocyte count, differential leukocyte count, platelet count, mean corpuscular volume (MCV), mean corpuscular hemoglobin (MCH), mean corpuscular hemoglobin concentration (MCHC), packed cell volume (PCV) and Erythrocyte sedimentation rate (ESR)

2. Peripheral blood smear study and reticulocyte count.

3. C - reactive protein.

4. S. LDH.

5. Urine R / M.

6. Liver function tests.

7. Kidney function tests.

8. Thyroid function test.

9. CXR.

10. USG Abdomen.

11. Iron profile.

12. Stool examination $-\mathrm{R} / \mathrm{M}$ and occult blood.

13. S Vitamin B12 and RBC folate level.

14. Bone Marrow examination if required.

15. $\mathrm{Hb}$ electrophoresis and protein electrophoresis if required.

16. Immunological study such as Coombs test, ANA and antidsDNA if required.

17. Viral study such as HBsAg, anti-HCV and HIV.

18. Gastrointestinal endoscopy if required.

19. FNAC and biopsy if required.

\section{Statistical Analysis}

The primary objective of this study was to assess the aetiology of anaemia in elderly patients. Descriptive statistics were attained from data collected from history, examinations and laboratory investigations. Numbers and percentages were enumerated for all categorical variables such as clinical findings, haematological investigations and bone marrow findings.

\section{RESULTS}

We included 100 cases in this study. The patients were subjected to a thorough clinical examination, lab investigation and a structured proforma was filled for each case. Collected data analysed and results are summarised as follows:

1. Sex - wise distribution - Out of 100 cases, 74 were males and 26 were females with male-to-female ratio of 2.84:1

2. Age - wise distribution (Table 1) Age ranges of elderly patient with anaemia ranges from 61 to 91 . Maximum number of cases was there in the age range of 61 to 70 
comprising $70 \%$ followed by $23 \%$ in 71 to 80 years age group and $6 \%$ in 81 to 90 years age group.

\begin{tabular}{|ccc|}
\hline Age & Frequency & Frequency in Percentage \\
$61-70$ & 70 & 70 \\
$71-80$ & 23 & 23 \\
$81-90$ & 6 & 6 \\
$91-100$ & 1 & 1 \\
\hline \multicolumn{3}{|c}{ Table 1. Age Wise Distribution } \\
\hline
\end{tabular}

3. Clinical features - Weakness was the most common presentation comprising $74 \%$ cases. Other clinical features were body pain in $10 \%$, dyspnoea in $7 \%$, loss of appetite in $6 \%$, fever in $5 \%$, vomiting in $5 \%$ and dysphagia in $1 \%$.

4. Prevalence of co morbidity - Solid malignancy including carcinoma breast and carcinoma oesophagus was there in $5 \%$, DM in $7 \%$, HT in $6 \%$, CKD in $5 \%$, Cor pulmonale in $3 \%$ and hypothyroidism in $1 \%$. One patient was having rheumatoid arthritis with history of methotrexate intake.

5. Categorisation based on severity of anaemia (Table 2) Patients were categorised in three category based on haemoglobin level which are as follows.

- Mild - Haemoglobin level 10 - 13 gm \%

- Moderate - Haemoglobin level 7 - 9.9 gm \%

- Severe - Haemoglobin level less than $6.9 \mathrm{gm} \%$

Based on the above criteria $48 \%$ patients were having moderate anaemia, $45 \%$ patients were having severe anaemia and $7 \%$ patients were having mild anaemia.

\begin{tabular}{|ccc|}
\hline Severity of Anaemia & Frequency & Frequency in Percentage \\
Mild & 7 & 7 \\
Moderate & 48 & 48 \\
Severe & 45 & 45 \\
\hline Table 2. Categorization of Anaemia Based on Severity \\
\hline
\end{tabular}

Distribution of anaemia as per morphology (Table 3) morphologically most common variety of anaemia was normocytic normochromic contributing $57 \%$ patients. This characterization was based on RBC indices and peripheral smear study. Out of 100 patients $10 \%$ showed dual red cell population on PBS and was classified as dimorphic anaemia. The highest value of MCV which was recorded was 134fL.

\begin{tabular}{|ccc|}
\hline Morphological Classification & Frequency & Frequency in Percentage \\
Normocytic Normochromic & 57 & 57 \\
Microcytic Hypochromic & 13 & 13 \\
Macrocytic Anaemia & 20 & 20 \\
Dimorphic Anaemia & 10 & 10 \\
\hline Table 3. Distribution of Anaemia as per Morphology \\
\hline
\end{tabular}

Bone marrow findings (Table 4) we did bone examinations in 62 patients. Out of 62 patients, 27 had hyper cellular marrow, 24 had normocellular and 06 had hypo cellular marrow. 05 patients had mildly hyper cellular to normocellular marrow. The pathology behind the hyper cellular marrow was predominantly because of haematological malignancy including myelodysplastic syndrome and acute leukemia. Out of 12 cases of multiple myeloma, 2 had hyper cellular marrow.

Aetiology of anaemia in elderly (Table 5) Out of 100 patients, aetiological distribution showed $14 \%$ each of ACD and vitamin B12 deficiency. This was closely followed by IDA
(13\%). In about $9 \%$ of cases the cause of anaemia remained unexplained and no aetiology could be established.

\begin{tabular}{|ccc|}
\hline Bone Marrow Findings & Frequency & Frequency in Percentage \\
Megaloblastic Anaemia & 5 & 5 \\
Iron Deficiency Anaemia & 4 & 4 \\
Nutritional Anaemia & 5 & 5 \\
Acute Leukemia & 9 & 9 \\
MDS & 10 & 10 \\
Multiple Myeloma & 12 & 12 \\
LD body & 1 & 1 \\
CLL & 1 & 1 \\
Normal & 9 & 9 \\
Hypoplastic Anaemia & 6 & 6 \\
\hline \multicolumn{2}{c}{ Table 4. Bone Marrow Findings } \\
\hline
\end{tabular}

\begin{tabular}{|ccc|}
\hline Aetiology & Frequency & Frequency in Percentage \\
Anaemia of Chronic Disease & 14 & 14 \\
Vitamin B12 Deficiency & 14 & 14 \\
IDA & 13 & 13 \\
Multiple Myeloma & 12 & 12 \\
MDS & 10 & 10 \\
Nutritional Anaemia & 10 & 10 \\
Acute Leukemia & 9 & 9 \\
Hypoplastic Anaemia & 6 & 6 \\
CLL & 1 & 1 \\
Kala Azar & 1 & 1 \\
Drug Induced & 1 & 1 \\
(Methotrexate) & 9 & 9 \\
Unexplained & Table 5. Aetiology of Anaemia in Elderly \\
\hline \multicolumn{2}{c}{}
\end{tabular}

\section{DISCUSSION}

In our study, out of 100 cases 74 were male and 26 were female with male to female ratio 2.84:1. Bist N, Sofia and Neki NS conducted a study on 1658 elderly patients and observed anaemia in 846 male and 812 female with a male to female ratio 1.04:1.8 The study conducted by Bhasin A, Rao MY on 100 patients observed male to female ratio of 1.08:1. ${ }^{9}$ Similar study done by Prakash KG et. al. and Mann S et al. found male to female ratio of 1.77:1 and 2.66:1 respectively which was close to our observation. . $^{10,11}$

In our study we found maximum number of patients visiting hospital were in the age range of 61 to 70 comprising $70 \%$ followed by $23 \%$ in the age range of 71 to $80,6 \%$ in 81 - 90 and $1 \%$ in more than 90 years age group. Bist N. et.al. found that $65.51 \%$ in the age group of $60-69,20.62 \%$ in 70 79 age group and $13.78 \%$ in more than 80 years which is comparable with our observation. ${ }^{8}$ In other studies also the maximum number of patients were in the similar age range.

In our study weakness was the most common presentation comprising $74 \%$ cases. Other clinical features were body pain in $10 \%$, dyspnoea in $7 \%$, loss of appetite in $6 \%$, fever in $5 \%$, vomiting in $5 \%$ and dysphagia in $1 \%$. Bhasin A. et al. observed fatigue as the most common symptom in $74 \%$ patients. This finding was followed by palpitation and anorexia in $13 \%$ cases and breathlessness in $11 \%$. Pallor was present in $59 \%$ patients, peripheral oedema in $20 \%$ and $25 \%$ having lymphadenopathy. ${ }^{9}$ Prakash KG et. al. observed easy fatigability as most common presentation in $88 \%$ patients followed by dyspnoea in $70 \%$, giddiness in $60 \%$, bleeding per rectum in $6 \%$ and hematemesis in $2 \%{ }^{10}$

In our study associated co morbidity was found in $28 \%$ of cases. Solid malignancy was there in $5 \%$ including carcinoma breast and carcinoma oesophagus, DM in $7 \%$, HT in $6 \%$, CKD in $5 \%$, Cor pulmonale in $3 \%$, and hypothyroidism in $1 \%$. One 
patient was having rheumatoid arthritis with history of methotrexate intake.

We observed moderate anaemia in $48 \%$ patients. $45 \%$ of patients were having severe anaemia and $7 \%$ patients were having mild anaemia. Mann S.et al. observed mild anaemia in $18.33 \%$ which was significantly more than ours. Moderate anaemia was $46.67 \%$ which was comparable with ours and severe anaemia was in $35 \%$ cases. ${ }^{11}$ Prakash KG et al. observed severe anaemia in $42 \%$ patients, moderate in $40 \%$ patients and mild in $18 \%$ patients. ${ }^{10}$

Majority of patients were normocytic normochromic contributing $57 \%$. Other type of anaemia was macrocytic in $20 \%$, microcytic in $13 \%$ and dimorphic in $10 \%$. Bhasin A, Rao MY observed normocytic anaemia in $64 \%$, microcytic anaemia in $30 \%$ and macrocytic / dimorphic anaemia in $6 \%$ cases. ${ }^{9}$ In other studies also they observed maximum patient showing normocytic normochromic anaemia on morphology. Mann S et al. observed normocytic normochromic anaemia in $50 \%$, microcytic hypochromic in $40 \%$ and macrocytic in $10 \%$. ${ }^{11}$ Prakash KG et al. observed normocytic in $52 \%$, microcytic in $32 \%$ and macrocytic in $16 \%$ cases. $^{10}$

In our study, anaemia of chronic disease was found in 14 $\%$ cases, vitamin B12 deficiency in $14 \%$, IDA in $13 \%$, multiple myeloma in $12 \%$, MDS in $10 \%$, nutritional in $10 \%$, acute leukemia in $9 \%$, hypo plastic in $6 \%$, CLL in 1, Kala azar in $1 \%$ and drug induced in $1 \%$. In $9 \%$ patients' aetiology could not be ascertained even after extensive evaluation. In our study, anaemia is associated with malignancy in $37 \%$ cases dominantly haematological malignancy. This high number of association with malignancy in our study is probably because our institute is the only tertiary care centre along with attached regional cancer centre in Bihar. Mann $\mathrm{S}$ et al. observed ACD in $41 \%$, IDA in $35 \%$, MDS in $5 \%$, myelofibrosis in $3.33 \%$, haemolytic in $3.33 \%$, megaloblastic in $3.33 \%$, aplastic in $1.66 \%$. and in $6.66 \%$ cases no cause was identified. ${ }^{11}$ Prakash KG et al. observed ACD in $26 \%$, IDA in 24 $\%$, haematological malignancy in $18 \%$, B12 deficiency in $8 \%$, CKD in $6 \%$, aplastic in $4 \%$, folate deficiency in $2 \%$, hypothyroidism in 25 , and upper GI bleed in $2 \%$ cases. In $8 \%$ cases no cause was identified. 10

\section{CONCLUSIONS}

Anaemia in elderly is a common clinical condition commonly presenting with nonspecific symptoms. Normocytic normochromic anaemia is the most common morphological type of anaemia with various underlying treatable aetiology.
Personalised approach is required for evaluation and aetiological management of anaemia in elderly.

Financial or Other Competing Interests: None.

\section{REFERENCES}

[1] Firkin F, Chesterman C, Penington D, et al. De Gruchy's clinical haematology in medical practice. $5^{\text {th }}$ edn. Delhi: Oxford University Press 1991:17-101.

[2] Fauci A, Braunwald E, Kasper D, et al. Hematopoietic disoders. In: Harrison's principles of internal medicine. Vol. 1. 17th edn. NewYork: McGraw Hill Medical 2008:62834, 643-51, 663-71.

[3] Kumar V. Geriatric Medicine. In: Munjal YP. API textbook of medicine. $9^{\text {th }}$ edn. Jaypee Brothers Medical Publishers 2012:2038-9.

[4] Ferrucci L, Studenski S. Clinical problem of aging. In: Kasper D, Fauci A, Hauser S, et al, eds. Harrison's principles of internal medicine. 19th edn. New York, NY: McGraw-Hill Education 2014:70-85.

[5] Witham MD. Aging and disease. In: Walker B, Colledge NR, Ralston S, et al, eds. Davidson's principle and practice of medicine. 22 $2^{\text {nd }}$ edn. Churchill Livingstone 2014.

[6] Culleton BF, Manns BJ, Zhang J, et al. Impact of anaemia on hospitalization and mortality in older adults. Blood 2006;107(10):3841-6.

[7] Kaushansky K, Lichtman MA, Beutler E, et al. William's hematolgy. $8^{\text {th }}$ edn. New York: McGraw Hill Medical 2011:115-22, 455-61, 495-501, 503-9, 533-57, 565-95, 1249-65.

[8] Bisht N, Sofia, Neki NS. Prevalence and pattern of anaemia in elderly - a hospital based study. Int J Curr Res Med Sci 2017;3(6):27-35.

[9] Bhasin A, Rao MY. Characteristics of anaemia in elderly: a hospital based study in South India. Indian J Hematol Blood Transfus 2011;27(1):26-32.

[10] Prakash KG, Devendrappa KR, Madhukumar MH, et al. Clinical profile of anaemia in elderly: a cross sectional study from a tertiary care centre. Sch J App Med Sci 2015;3(3C):1266-70.

[11] Mann S, Kumar A, Singh SK, et al. Clinical evaluation of anaemia in geriatric patients - a cross sectional study conducted at tertiary care hospital. Natl J Community Med 2014;5(3):316-20. 